\title{
Effect of fluxing additive on sintering temperature, microstructure and properties of $\mathrm{BaTiO}_{3}$
}

\author{
YASEEN IQBAL**,ASAD JAMAL, RIAZ ULLAH, M NAEEM KHAN and RICK UBIC ${ }^{\dagger}$ \\ Materials Research Laboratory, Institute of Physics \& Electronics, University of Peshawar, Peshawar 25120, Pakistan \\ ${ }^{\dagger}$ College of Engineering, Boise State University, Idaho, USA
}

MS received 15 June 2011; revised 30 July 2011

\begin{abstract}
Various fluxing materials are added to technical ceramics in an attempt to lower their sintering temperatures and make their processing economical. The effect of $0.3 \mathrm{wt} \% \mathrm{Li}_{2} \mathrm{CO}_{3}$ addition on the phase, microstructure, phase transition temperatures and dielectric properties of $\mathrm{BaTiO}_{3}$ was investigated in the present study. The addition of $0.3 \mathrm{wt} \% \mathrm{Li}_{2} \mathrm{CO}_{3}$ was observed to lower the optimum sintering temperature by $\sim 200^{\circ} \mathrm{C}$ with no second phase formation and cause a five-fold reduction in grain size. Rhombohedral-to-orthorhombic and tetragonal-to-cubic phase transitions at the expected temperatures were evident from the Raman spectra, but the orthorhombic-totetragonal phase transition was not clearly discernible. The persistence of various phase(s) at higher temperatures in the flux-added materials indicated that the phase transitions occurred relatively slowly. A decrease in dielectric constant of $\mathrm{Li}_{2} \mathrm{O}$-added $\mathrm{BaTiO}_{3}$ in comparison to pure $\mathrm{BaTiO}_{3}$ may be due to the diminished dielectric polarizability of $\mathrm{Li}^{+}$in comparison to $\mathrm{Ba}^{2+}$.
\end{abstract}

Keywords. Electronic materials; Raman spectroscopy; dielectric properties; microstructure.

\section{Introduction}

Barium meta-titanate $\left(\mathrm{BaTiO}_{3}\right)$ is widely used in electronic devices, such as multilayer ceramic capacitors (MLCCs), tunable filters and piezoelectric sensors due to its high chemical and mechanical stability, ferroelectric properties at and above room temperature, easy preparation methods and high dielectric constant (Wul 1945; Bunting et al 1947). It is also used in positive temperature coefficient resistors (PTCR) such as thermistors, electroluminescent panels and pyroelectric elements. Its global production is $\sim 11 \times 10^{6} \mathrm{~kg} /$ annum and the MLCC industry alone is a multi-billion dollar industry in which more than 10 billion units are produced annually (O'Bryan and Thomson 1974; Scott 1993; Swartz and Shrout 1997; Bell 2008).

$\mathrm{BaTiO}_{3}$ was discovered in 1839 and became the first useful ferroelectric material with a perovskite-type structure (Wul 1945). An early example of an application of $\mathrm{BaTiO}_{3}$ was the unprecedented achievement of high specific capacitance made possible by the modification of $\mathrm{BaTiO}_{3}$ with isovalent substitutions (e.g. $\mathrm{Sr}^{2+}$ ) in order to shift the Curie temperature $\left(T_{\mathrm{C}}\right)$ closer to room temperature (Jaffe and Cook 1971; Scott 1993). From the late 1940s, efforts have been underway to produce highly homogeneous, fully dense, multi-component oxides to tailor dielectric properties for commercial use (Batllo et al 1990; Heartling 1999; Langhammaer et al 2000; Masion et al 2003; Millsch 2006). The classic $\mathrm{BaO}-\mathrm{TiO}_{2}$

\footnotetext{
*Author for correspondence (dryaseeniqbal@yahoo.co.uk)
}

phase equilibrium diagram of Rase and Roy (O'Bryan and Thomson 1974) shows the presence of a $1317^{\circ} \mathrm{C}$ eutectic close to the $\mathrm{BaTi}_{2} \mathrm{O}_{5}$ composition which was later identified as $\mathrm{Ba}_{6} \mathrm{Ti}_{17} \mathrm{O}_{40}$.

$\mathrm{BaTiO}_{3}$ is a ferroelectric ceramic material with a perovskite structure. It has four polymorphs, viz. rhombohedral, orthorhombic, tetragonal and cubic. There is also an hexagonal form which is stable above $\sim 1430^{\circ} \mathrm{C}$. The tetragonal form of $\mathrm{BaTiO}_{3}$ is stable at room temperature, whereas the cubic form is stable at high temperatures $\left(>120^{\circ} \mathrm{C}\right)$. All forms have a relatively high dielectric constant (Pasha et al 2007). Cubic $\mathrm{BaTiO}_{3}$ has one dielectric constant denoted by $\varepsilon_{\mathrm{r}}$ whereas the dielectric constant of tetragonal $\mathrm{BaTiO}_{3}$ consists of two components, denoted by $\varepsilon_{\mathrm{a}}$ and $\varepsilon_{\mathrm{c}}$, corresponding to directions perpendicular and parallel to the polar axis. At room temperature, the numerical value of its spontaneous polarization is $26 \times 10^{-2} \mathrm{C} / \mathrm{cm}^{2}$.

Most of the commercial electroceramics compositions are modified via doping in one way or another; and processing, phase and microstructural studies of some basic compositions leading to their improved densification and properties accompanied by lowering of the sintering temperature are always sought. Such studies have been crucial in pointing the way towards modern dielectric formulations. For example, $\mathrm{BaTiO}_{3}$-based ceramics with a $1 \mu \mathrm{m}$ grain size have been produced via fast-firing with a three-fold increase in permittivity over the coarse-grained material. Anan'eva et al (1960) reported an almost six-fold increase in permittivity by similar techniques. The origin of this anomalous effect is still under discussion over 50 years later. This continuous struggle has 
not just been a scientific curiosity but has lead to the development of modern capacitor dielectrics. The exploitation of this effect in X7R dielectric materials required an indepth understanding of chemistry. It is now known that donor dopants inhibit grain growth, providing a means of exploiting the anomalous grain size effect without exotic thermal processing; however, donor doping also affects electrical conductivity in $\mathrm{BaTiO}_{3}$ (Anan'eva et al 1960; Desu and Subbarao 1981; Manczok and Wernicke 1983; Wang 2002; Masion et al 2003); therefore, a thorough understanding of the compensation mechanism by acceptor additions is required (Galasso 1996).

The effect of various fluxing additives on the phase, microstructure and properties of $\mathrm{BaTiO}_{3}$ are constantly investigated in an attempt to lower its sintering temperature and reduce processing cost; but such additions result in the formation of second phases or pores, leading to deterioration of properties. For example, the addition of $3 \mathrm{~mol} \% \mathrm{BaB}_{2} \mathrm{O}_{4}$ to sol-gel-derived semiconducting Y-doped $\mathrm{BaTiO}_{3}$ has been reported to lower its sintering temperature to $1050^{\circ} \mathrm{C}$; however, $\mathrm{BaB}_{2} \mathrm{O}_{4}$ not only forms a non-conductive amorphous phase, but the volatilization of a boron-rich liquid phase leads to the formation of pores which adversely affect the density of ceramics (Kong et al 2009). Similarly, the addition of $>5 \mathrm{wt} \%$ of the $60.7 \mathrm{ZnO}-24.9 \mathrm{~B}_{2} \mathrm{O}_{3}-14.4 \mathrm{SiO}_{2}(\mathrm{~mol} \%)$ glass has been reported to enable the sintering of $\mathrm{BaTiO}_{3}$ to $95 \%$ of theoretical density at temperatures as low as $900^{\circ} \mathrm{C}$ without the formation of a second phase, but with a dielectric constant of only 994 (Hsiang et al 2009).

The addition of small amounts of $\mathrm{Li}_{2} \mathrm{O}$ to various ceramic compositions has been reported to lower the sintering temperature by various mechanisms. In aluminium nitride (AlN), the addition of $\mathrm{Li}_{2} \mathrm{O}$ has been observed to densify the material at a lower temperature $\left(\sim 1650^{\circ} \mathrm{C}\right.$ ) than pure AlN (sintering temperature $>1800^{\circ} \mathrm{C}$ ) due to the formation of a Li-containing liquid phase at $\sim 1100^{\circ} \mathrm{C}$. Additionally, the volatilization of a Li-containing phase at high temperatures purifies the grain boundaries of the parent material (Qiao et al 2003). Similarly, $\mathrm{Li}_{2} \mathrm{CO}_{3}$ addition to $\mathrm{SrTiO}_{3}$, has also been observed to lower its sintering temperature but simultaneously form Li-containing second phase(s) which could be eliminated either by controlling the amount of $\mathrm{Li}_{2} \mathrm{CO}_{3}$ added or sintering the ceramic at a high temperature to eliminate the volatile Li-containing phase (Cheng et al 1989). The addition of $\mathrm{Li}_{2} \mathrm{CO}_{3}$ to $\mathrm{BaTiO}_{3}-\mathrm{Nb}_{2} \mathrm{O}_{5}-\mathrm{La}_{2} \mathrm{O}_{3}-\mathrm{Sm}_{2} \mathrm{O}_{3}$ has been reported to improve the dielectric constant at temperatures near the Curie temperature ( $\mathrm{Li}$ et al 2001). The addition of $0.3 \mathrm{wt} \% \mathrm{Li}_{2} \mathrm{O}$ in the form of polycrystalline $\mathrm{Li}_{2} \mathrm{O}, \mathrm{Li}_{2} \mathrm{CO}_{3}$ or as an ascetic solution of $\mathrm{Li}^{+}$ions to $\mathrm{BaTiO}_{3}$ has been observed to lower its sintering temperature by $\sim 400^{\circ} \mathrm{C}$ (from $\sim 1250^{\circ} \mathrm{C}$ to $820^{\circ} \mathrm{C}$ ), independent of the form of $\mathrm{Li}_{2} \mathrm{O}$ added. It has been reported that $\mathrm{Li}_{2} \mathrm{O}$ and $\mathrm{BaTiO}_{3}$ first reacted to form $\mathrm{BaCO}_{3}$ and $\mathrm{Li}_{2} \mathrm{TiO}_{3}$ at $600^{\circ} \mathrm{C}$. These pre-reacted powders when milled and compacted, sinter to $>95 \%$ of the relevant theoretical density at $820^{\circ} \mathrm{C}$, but result in the retention of $\mathrm{Li}_{2} \mathrm{TiO}_{3}$ and $\mathrm{Ba}_{2} \mathrm{TiO}_{4}$ in small concentrations (Valant et al 2006).

In this study, results regarding the phase, microstructure and dielectric properties of $\mathrm{BaTiO}_{3}$ prepared via a mixedoxide route and a reactive-phase sintering route via donor doping have been described and discussed. Additionally, in situ Raman spectroscopy has been used for the first time to investigate and compare the phase transition temperatures of pure and $\mathrm{Li}_{2} \mathrm{CO}_{3}$-added $\mathrm{BaTiO}_{3}$.

\section{Experimental}

Batches $(50 \mathrm{~g})$ of GPR grade $\mathrm{TiO}_{2}$ and $\mathrm{BaCO}_{3}$ (Aldrich Chemicals Company Inc.) powder were prepared and mixmilled for $24 \mathrm{~h}$ in a horizontal ball mill with Y-PSZ balls as milling media and 2-propanol as lubricant. The resulting slurry was poured through a sieve into a glass beaker and dried at $\sim 90^{\circ} \mathrm{C}$ overnight. After sieving, the resulting powder samples were calcined at $900^{\circ} \mathrm{C}$ for $2 \mathrm{~h}$, with a heating/ cooling rate of $10^{\circ} \mathrm{C} / \mathrm{min}$. The calcined powders were remilled for $30 \mathrm{~min}$ to dissociate agglomerates, dried, sieved and pressed into $13 \mathrm{~mm}$ diameter pellets at $100 \mathrm{MPa}$. The pellets were sintered at $1250^{\circ} \mathrm{C}$ for $2 \mathrm{~h}$ with a heating/cooling

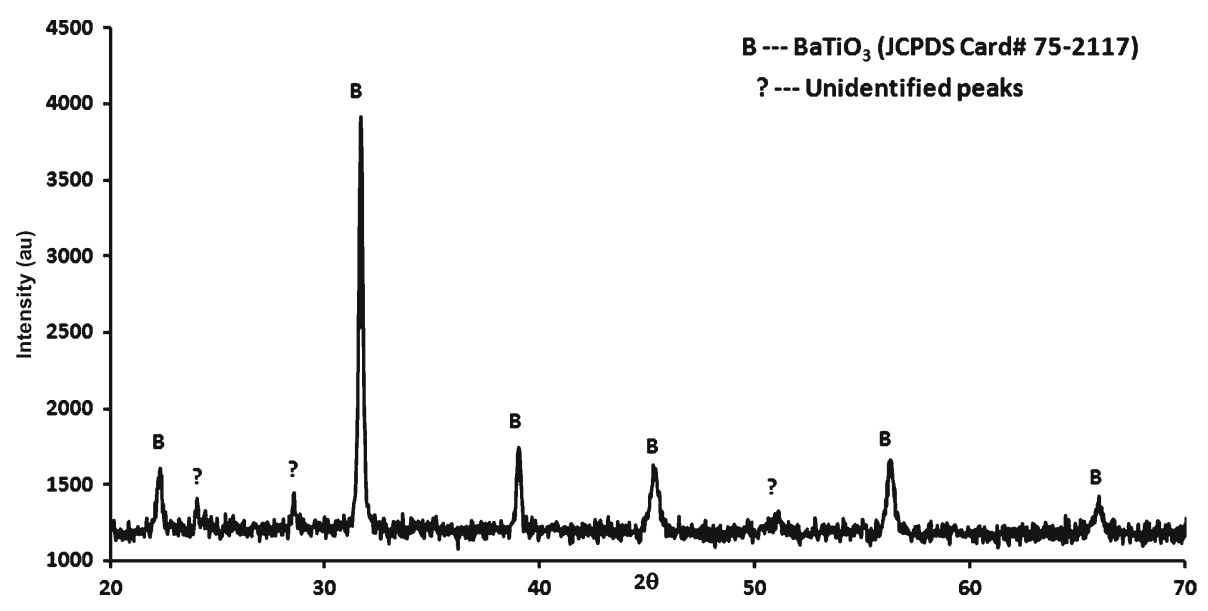

Figure 1. X-ray diffractogram of $\mathrm{BaTiO}_{3}$ calcined at $900^{\circ} \mathrm{C}$ showing the formation of tetragonal $\mathrm{BaTiO}_{3}$ phase along with a couple of low intensity peaks, showing incomplete reaction. 
rate of $5^{\circ} \mathrm{C} / \mathrm{min}$. The reactive-phase sintering route was the same as the mixed-oxide route except that $0.3 \mathrm{wt} \% \mathrm{Li}_{2} \mathrm{CO}_{3}$ sintering aid was added and milled-in after calcination. The phase analysis of the samples was carried out using an X-ray diffractometer (XRD) (1700 series, Philips, The Netherlands) with $\mathrm{CuK} \alpha$ radiation operating at $40 \mathrm{kV}$ and $30 \mathrm{~mA}$ with a step size of $0.02^{\circ}$ from 10 to $70^{\circ}$ at $1^{\circ} / \mathrm{min}$. For microstructural characterization a scanning electron microscope (SEM) (JSM-5910, JEOL, Japan) operating at 15$20 \mathrm{kV}$ was used. The sintered samples were cut into two pieces by a fine diamond wafering blade before fine polishing. The samples were thermally etched at temperatures $\sim 10 \%$ lower than the relevant sintering temperatures at $5^{\circ} \mathrm{C} / \mathrm{min}$ for $30 \mathrm{~min}$ to resolve the grains. To provide a conducting medium and avoid charging in the SEM, the samples were mounted on metallic stubs with silver paint and goldcoated. Electrical properties of pellets were measured using an LCR meter (model 4287A, HP, USA) from $R T-300^{\circ} \mathrm{C}$ at $1 \mathrm{kHz}-1 \mathrm{MHz}$. Density of the sintered samples was measured using an electronic densitometer (MD-300S, Lako Tool and Manufacturing Inc, Ohio, USA). In situ Raman spectroscopy was performed to determine and compare the phase transition temperatures using a micro-Raman spectrometer (Renishaw InVia) with $514.5 \mathrm{~nm}$ line of Ar-laser in the $100-1000 \mathrm{~cm}^{-1}$ range at $5^{\circ} \mathrm{C}$ interval from -190 to $300^{\circ} \mathrm{C}$.

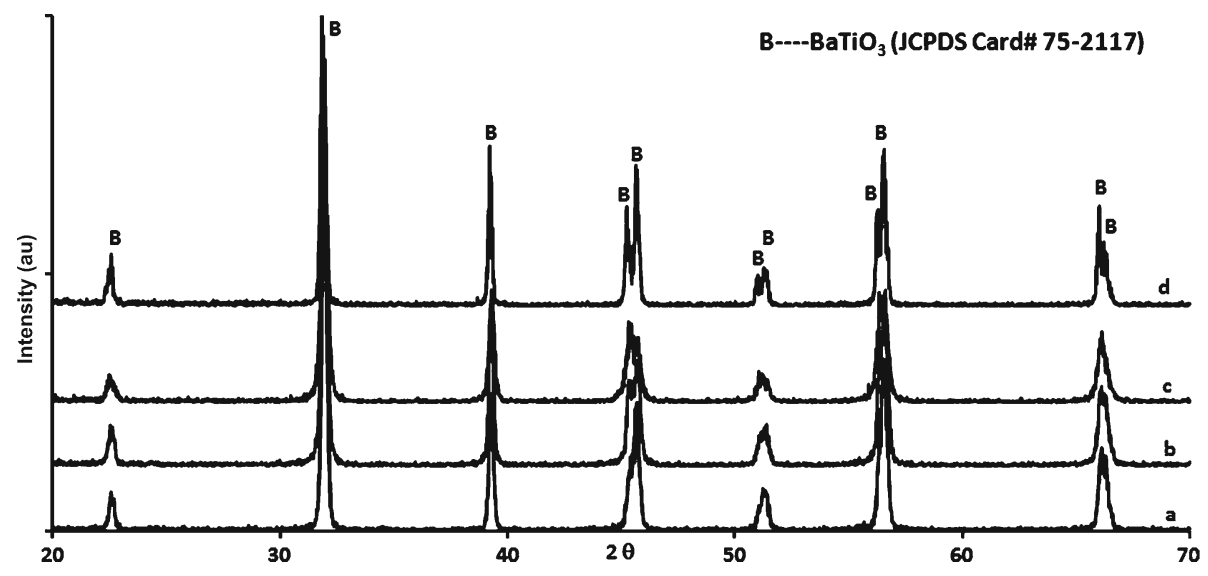

Figure 2. X-ray diffractogram of $\mathrm{Li}_{2} \mathrm{CO}_{3}$-added $\mathrm{BaTiO}_{3}$ calcined at $900^{\circ} \mathrm{C}$ and sintered at (a) $1000^{\circ} \mathrm{C}$, (b) $1050^{\circ} \mathrm{C}$ and (c) $1100^{\circ} \mathrm{C}$ showing formation of tetragonal $\mathrm{BaTiO}_{3}$ phase only. (d) is from pure $\mathrm{BaTiO}_{3}$ sample, calcined at $900^{\circ} \mathrm{C}$ and sintered at $1250^{\circ} \mathrm{C}$.
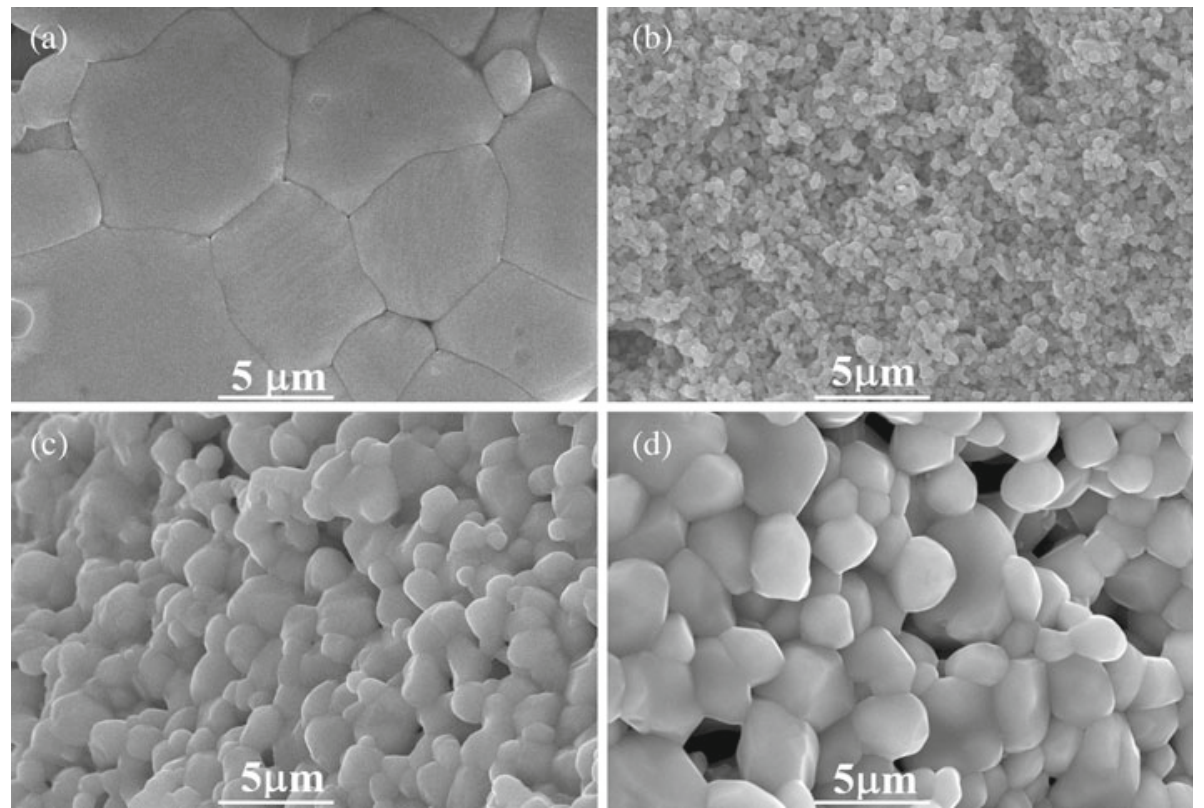

Figure 3. SEI from (a) pure $\mathrm{BaTiO}_{3}$ sample calcined at $900^{\circ} \mathrm{C}$ and sintered at $1250^{\circ} \mathrm{C}$ for $2 \mathrm{~h}$ showing $\sim 2$ to $10 \mu \mathrm{m} \mathrm{BaTiO} 3$ grains, (b) $0.3 \mathrm{wt} \% \mathrm{Li}_{2} \mathrm{CO}_{3}$-added $\mathrm{BaTiO}_{3}$ sample, calcined at $900^{\circ} \mathrm{C}$, showing $\leq 0.5 \mu \mathrm{m}$ grains in sample sintered at $1000^{\circ} \mathrm{C}$, (c) $1-1.5 \mu \mathrm{m}$ grains in sample sintered at $1050^{\circ} \mathrm{C}$ and (d) $1-2 \mu \mathrm{m}$ grains in sample sintered at $1100^{\circ} \mathrm{C}$. 


\section{Results and discussion}

Tetragonal $\mathrm{BaTiO}_{3}$ (PDF\# 75-2117) was the major phase identified by XRD in the sample calcined at $900^{\circ} \mathrm{C}$; however, the presence of a couple of low-intensity XRD peaks labelled as '?' which could not be identified were indicated as incomplete reaction at the calcination temperature (figure 1). All the inter-planar spacings ( $d$-values) and relevant intensities of XRD peaks from the sample calcined at $900^{\circ} \mathrm{C}$ and sintered at $1250^{\circ} \mathrm{C}$ matched with PDF\# 75-2117 for tetragonal $\mathrm{BaTiO}_{3}$ (figure 2d). The absence of extra peaks in this XRD pattern confirmed phase purity of the final ceramics. The $d$-values corresponding to XRD peaks from $0.3 \mathrm{wt} \% \mathrm{Li}_{2} \mathrm{CO}_{3}$ added samples calcined at $900^{\circ} \mathrm{C}$ and sintered at $1000^{\circ} \mathrm{C}, 1050^{\circ} \mathrm{C}$ and $1100^{\circ} \mathrm{C}$ also matched with PDF\# 75-2117 for tetragonal $\mathrm{BaTiO}_{3}$ (figures 2a-c). The asymmetry of the peaks at $2 \theta \sim 45.5^{\circ}, 51^{\circ}, 56.5^{\circ}$ and $66^{\circ}$ corresponding to (200), (201), (2 11 1) and (220) planes for
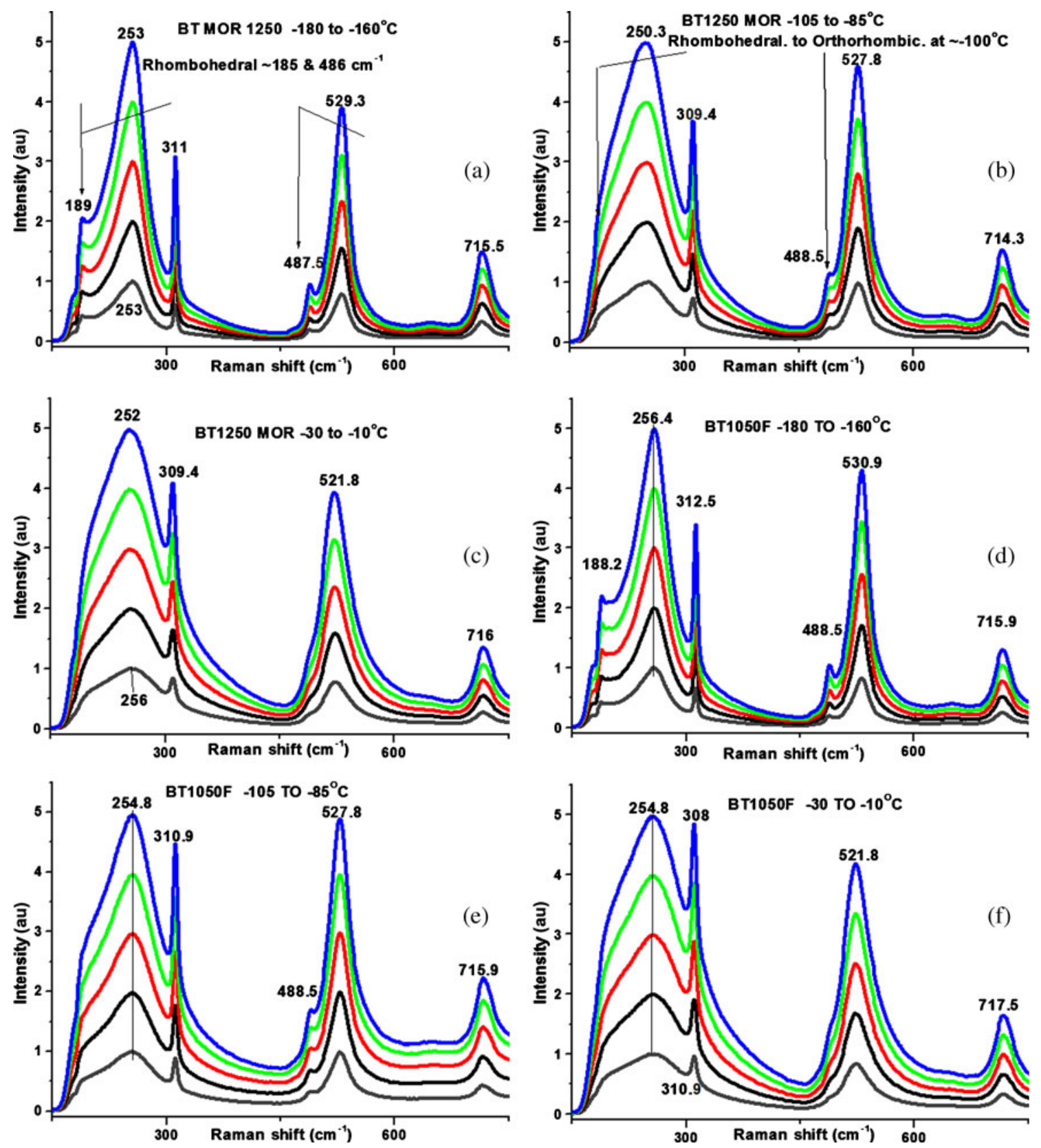

Figure 4. Raman spectra from pure $\mathrm{BaTiO}_{3}$ sample collected at (a) -180 to $-160^{\circ} \mathrm{C},(\mathbf{b})-105$ to $-85^{\circ} \mathrm{C}$ and $(\mathbf{c})-30$ to $-10^{\circ} \mathrm{C}$, and $\mathrm{Li}_{2} \mathrm{CO}_{3}$-added samples at $(\mathbf{d})-180$ to $-160^{\circ} \mathrm{C}$, (e) -105 to $-85^{\circ} \mathrm{C}$ and $(\mathbf{f})-30$ to $-10^{\circ} \mathrm{C}$. Note the presence of peaks at $\sim 189$ and $487 \mathrm{~cm}^{-1}$ indicative of rhombohedral phase collected at -180 to $-160^{\circ} \mathrm{C}$ (figures (a) and (d)) and their partial disappearance at -105 to $-85^{\circ} \mathrm{C}$ (figures (b) and (e)) and disappearance at -30 to $-10^{\circ} \mathrm{C}$ (figures (c) and (f)). 
samples sintered at $1000-1100^{\circ} \mathrm{C}$ indicated that all the peaks visible at $1250^{\circ} \mathrm{C}$ were present but were too broad to be clearly resolved due to small crystal size. It is noticeable that no extra XRD peaks due to second phase(s) or remnant starting powders due to incomplete reaction could be observed on any of these XRD patterns, demonstrating the phase-purity of the final ceramics within the detection limits of XRD in the present study. The previously reported presence of small amounts of $\mathrm{Li}_{2} \mathrm{TiO}_{3}$ and $\mathrm{Ba}_{2} \mathrm{TiO}_{4}$ in $0.3 \mathrm{wt} \% \mathrm{Li}_{2} \mathrm{CO}_{3}$-added
$\mathrm{BaTiO}_{3}$ sintered at $820^{\circ} \mathrm{C}$ may be due to the much lower sintering temperature, indicative of incomplete reaction (Valant et al 2006).

Secondary electron SEM images (SEI) from the $\mathrm{BaTiO}_{3}$ samples prepared via the mixed-oxide route calcined at $900^{\circ} \mathrm{C}$ and sintered at $1250^{\circ} \mathrm{C}$ for $2 \mathrm{~h}$ show grain sizes from $\sim 2$ to $10 \mu \mathrm{m}$ (figure 3a). Contrastingly, pure $\mathrm{BaTiO}_{3}$ samples heated at temperatures $\leq 1100^{\circ} \mathrm{C}$ were not dense and could be scratched with a finger nail. On the other hand,
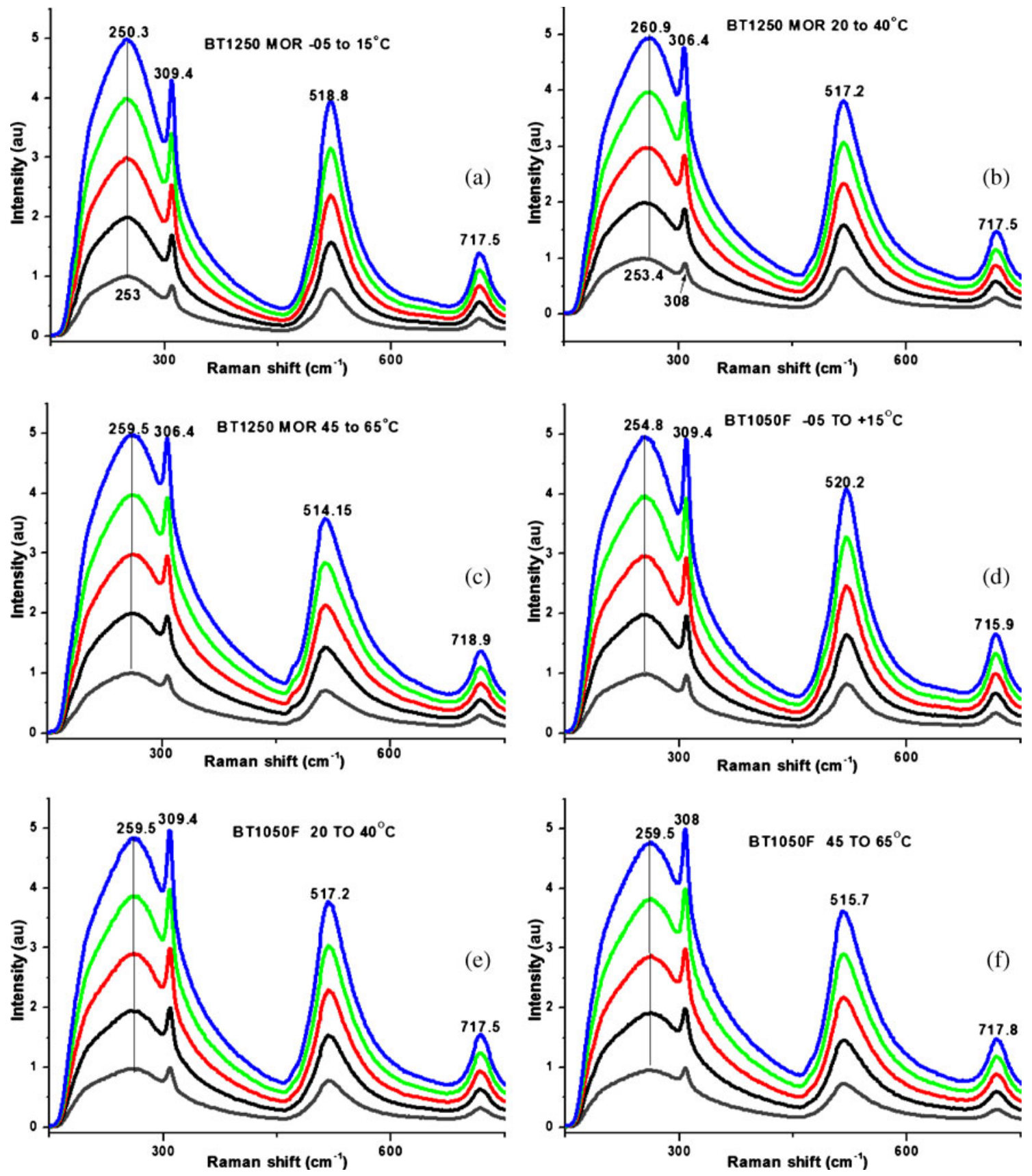

Figure 5. Raman spectra from pure $\mathrm{BaTiO}_{3}$ samples collected at $(\mathbf{a})-5$ to $+15^{\circ} \mathrm{C}$, (b) $20-40^{\circ} \mathrm{C}$ and $(\mathbf{c}) 45-65^{\circ} \mathrm{C}$, and $\mathrm{Li}_{2} \mathrm{CO}_{3}$-added samples at (d) -5 to $+15^{\circ} \mathrm{C}$, (e) $20-40^{\circ} \mathrm{C}$ and (f) $45-65^{\circ} \mathrm{C}$. Note the asymmetry of the peak at $\sim 518.8 \mathrm{~cm}^{-1}$ and at $\sim 10^{\circ} \mathrm{C}$, indicative of orthorhombic-to-tetragonal phase transition (Galasso 1996); however, a careful examination shows that this asymmetry is visible even at temperatures above and below $10^{\circ} \mathrm{C}$. 
the deformation of $\mathrm{Li}_{2} \mathrm{CO}_{3}$-added samples showed the beginning of melting upon sintering at temperatures $>1100^{\circ} \mathrm{C}$. The maximum density of pure $\mathrm{BaTiO}_{3}$ measured in this study was $4.75 \mathrm{~g} / \mathrm{cm}^{3}$. The density of $\mathrm{Li}_{2} \mathrm{CO}_{3}$-added $\mathrm{BaTiO}_{3}$ varied from 4.20 to $4.73 \mathrm{~g} / \mathrm{cm}^{3}$ with increase in the sintering temperature from 1000 to $1050^{\circ} \mathrm{C}$, which demonstrated $\sim 200^{\circ} \mathrm{C}$ decrease in the sintering temperature in comparison to pure $\mathrm{BaTiO}_{3}$. Upon further increase in the sintering temperature to $1100^{\circ} \mathrm{C}$, the density decreased to $4.5 \mathrm{~g} / \mathrm{cm}^{3}$.

The microstructure of $0.3 \mathrm{wt} \% \quad \mathrm{Li}_{2} \mathrm{CO}_{3}$-added $\mathrm{BaTiO}_{3}$ sample calcined at $900^{\circ} \mathrm{C}$ and fired at $1000^{\circ} \mathrm{C}$ comprised $\leq 0.5 \mu \mathrm{m}$ grains (figure $3 \mathrm{~b}$ ). This sample did not appear dense visually; however, the observed light necking of the grains
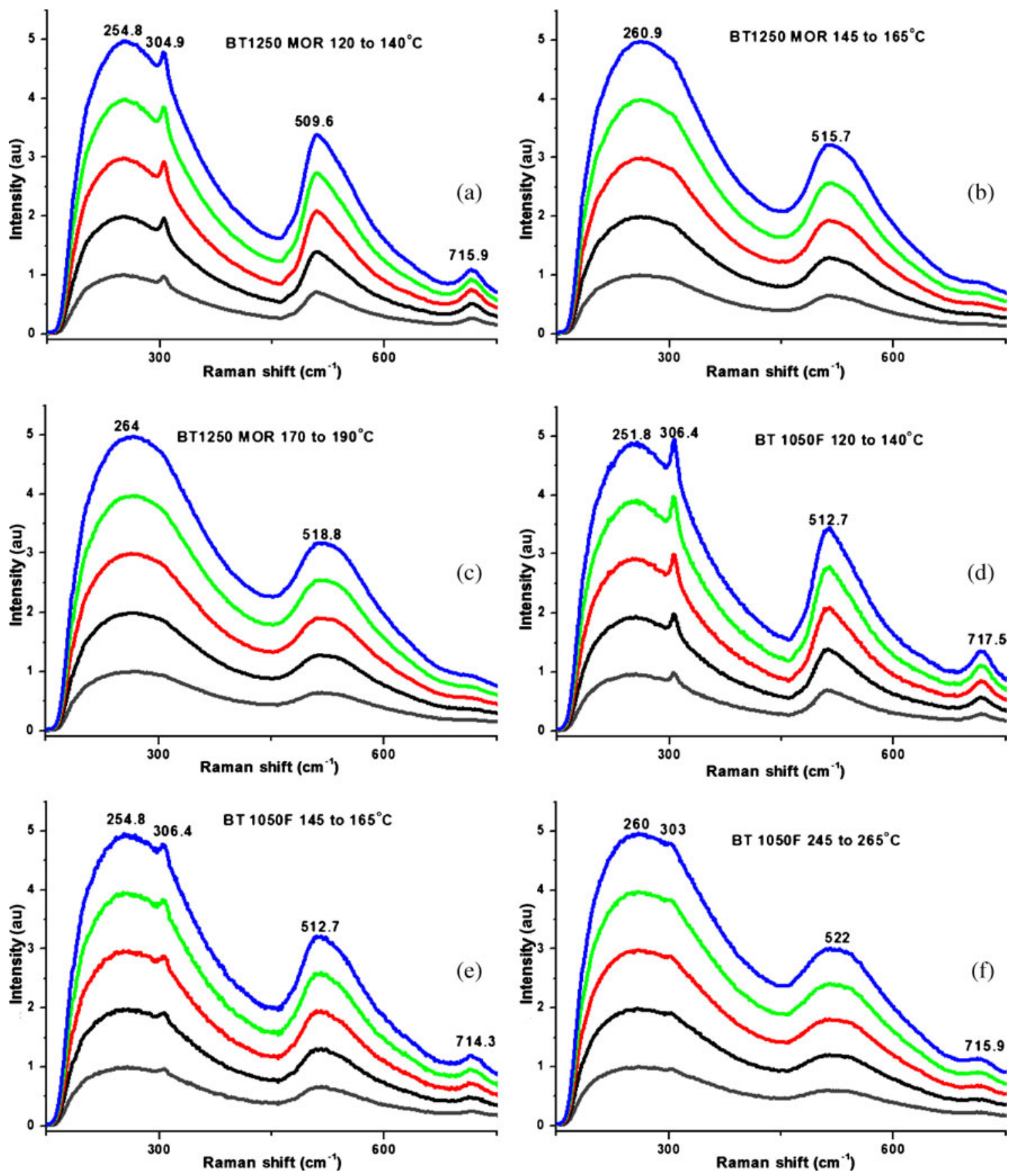

Figure 6. Raman spectra from pure $\mathrm{BaTiO}_{3}$ samples collected at (a) $120-140^{\circ} \mathrm{C}$, (b) $145-165^{\circ} \mathrm{C}$ and $(\mathbf{c}) 170-190^{\circ} \mathrm{C}$, and $\mathrm{Li}_{2} \mathrm{CO}_{3}$-added samples at (d) $120-140^{\circ} \mathrm{C}$, (e) $145-165^{\circ} \mathrm{C}$ and (f) $245-265^{\circ} \mathrm{C}$. Note the presence (figures (a) and (d)) and disappearance (figures (b) and (e)) of Raman peaks at $\sim 305$ and $306 \mathrm{~cm}^{-1}$ indicative of tetragonal-to-cubic phase transition at $\sim 124^{\circ} \mathrm{C}$. Note the presence of a small peak at $303 \mathrm{~cm}^{-1}$ till $220^{\circ} \mathrm{C}$ on spectra from $\mathrm{Li}_{2} \mathrm{CO}_{3}$ containing samples and not from pure $\mathrm{BaTiO}_{3}$ samples, showing relatively slower phase transition in flux-added samples. 
and disappearance of sharp edges of the grains indicated the beginning of densification (figure $3 b$ ).

As shown in figure 3(c), the grain size increased from $\sim 1$ to $1.5 \mu \mathrm{m}$ upon increasing the sintering temperature to $1050^{\circ} \mathrm{C}$, indicating more than 5 -fold decrease in the grain size of $\mathrm{BaTiO}_{3}$. Similarly, upon further increasing the sintering temperature to $1100^{\circ} \mathrm{C}$, the grain size continued to increase up to $\sim 2 \mu \mathrm{m}$. The grain size in dense pure $\mathrm{BaTiO}_{3}$ sample (sintered at $1250^{\circ} \mathrm{C}$ ) varied from 5 to $10 \mu \mathrm{m}$ and that of the $\mathrm{Li}_{2} \mathrm{CO}_{3}$-added samples varied from $\leq 1$ to $\leq 2 \mu \mathrm{m}$ (at 1050 and $1100^{\circ} \mathrm{C}$ ) which indicated that the addition of $\mathrm{Li}_{2} \mathrm{CO}_{3}$ not only decreased the sintering temperature associated with the maximum density achieved in this study by $\sim 150^{\circ} \mathrm{C}$ but the grain size also decreased by about $80 \%$ in comparison to pure $\mathrm{BaTiO}_{3}$ samples.

The disappearance of peaks at $\sim 189$ and $487 \mathrm{~cm}^{-1}$ in the Raman spectrum of pure $\mathrm{BaTiO}_{3}$ samples sintered at $1250^{\circ} \mathrm{C}$ indicated the transition of rhombohedral-to-orthorhombic phase at about $-100^{\circ} \mathrm{C}$ (figures $4 \mathrm{a}-\mathrm{c}$ ) which is consistent with previous studies (Pasha et al 2007). Similarly, in $\mathrm{Li}_{2} \mathrm{CO}_{3}$-added samples sintered at $1050^{\circ} \mathrm{C}$, these peaks disappeared at slightly higher temperatures, indicting slow phase transition in $\mathrm{Li}_{2} \mathrm{CO}_{3}$-containing samples (figures $4 \mathrm{~d}-\mathrm{f}$ ). The asymmetry of the peak at $512 \mathrm{~cm}^{-1}$ and at $\sim 10^{\circ} \mathrm{C}$ was considered to be indicative of orthorhombic-to-tetragonal phase transition (Pasha et al 2007); however, in the present study, the asymmetry of the peak at $\sim 520 \mathrm{~cm}^{-1}$ could be observed not only at $\sim 10^{\circ} \mathrm{C}$ but at temperatures below and above $10^{\circ} \mathrm{C}$ as well (figures $5 \mathrm{a}-\mathrm{f}$ ) which may be due to gradual orthorhombic-to-tetragonal phase transition. The disappearance of the Raman peak at $\sim 308 \mathrm{~cm}^{-1}$ indicated the transition from the tetragonal to the cubic phase at $\sim 124^{\circ} \mathrm{C}$ (figures $6 \mathrm{a}-\mathrm{c}$ ). Unlike the case for pure $\mathrm{BaTiO}_{3}$, a small peak at $\sim 308 \mathrm{~cm}^{-1}$ was visible up to $220^{\circ} \mathrm{C}$ in the spectra of $\mathrm{Li}_{2} \mathrm{CO}_{3}$-containing samples (figures $6 \mathrm{~d}-\mathrm{f}$ ). For undoped $\mathrm{BaTiO}_{3}$, Pasha et al (2007) reported the presence of modes at 303 and $710 \mathrm{~cm}^{-1}$ at temperatures above $T_{\mathrm{c}}$ which persisted at temperatures even above $180^{\circ} \mathrm{C}$.

For pure $\mathrm{BaTiO}_{3}$, the highest value of dielectric constant was $\sim 1500$ at $127^{\circ} \mathrm{C}$ measured at $1 \mathrm{kHz}-1 \mathrm{MHz}$ (figure 7a), whereas for the $\mathrm{Li}_{2} \mathrm{CO}_{3}$-added samples it was 450 at $124^{\circ} \mathrm{C}$ in the same frequency range (figure $7 \mathrm{~b}$ ). The decrease in $\varepsilon_{\mathrm{r}}$ may be due to the diminished dielectric polarizability of $\mathrm{Li}^{+}$ $\left(1 \cdot 20 \AA^{3}\right)$ compared to $\mathrm{Ba}^{2+}\left(6 \cdot 40 \AA^{3}\right)$ (Shannon 1993). The
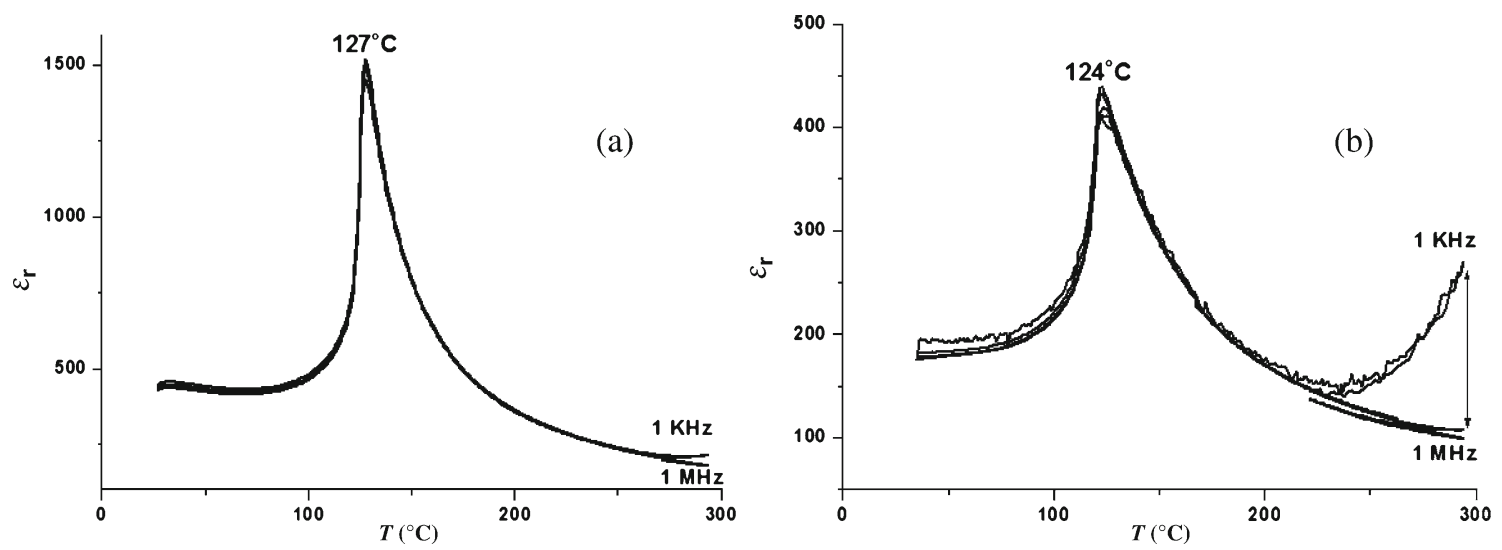

Figure 7. Variation in relative permittivity with temperature for (a) pure $\mathrm{BaTiO}_{3}$ sintered at $1250^{\circ} \mathrm{C}$ and $(\mathbf{b}) \mathrm{Li}_{2} \mathrm{CO}_{3}-$ added $\mathrm{BaTiO}_{3}$ sintered at $1050^{\circ} \mathrm{C}$.
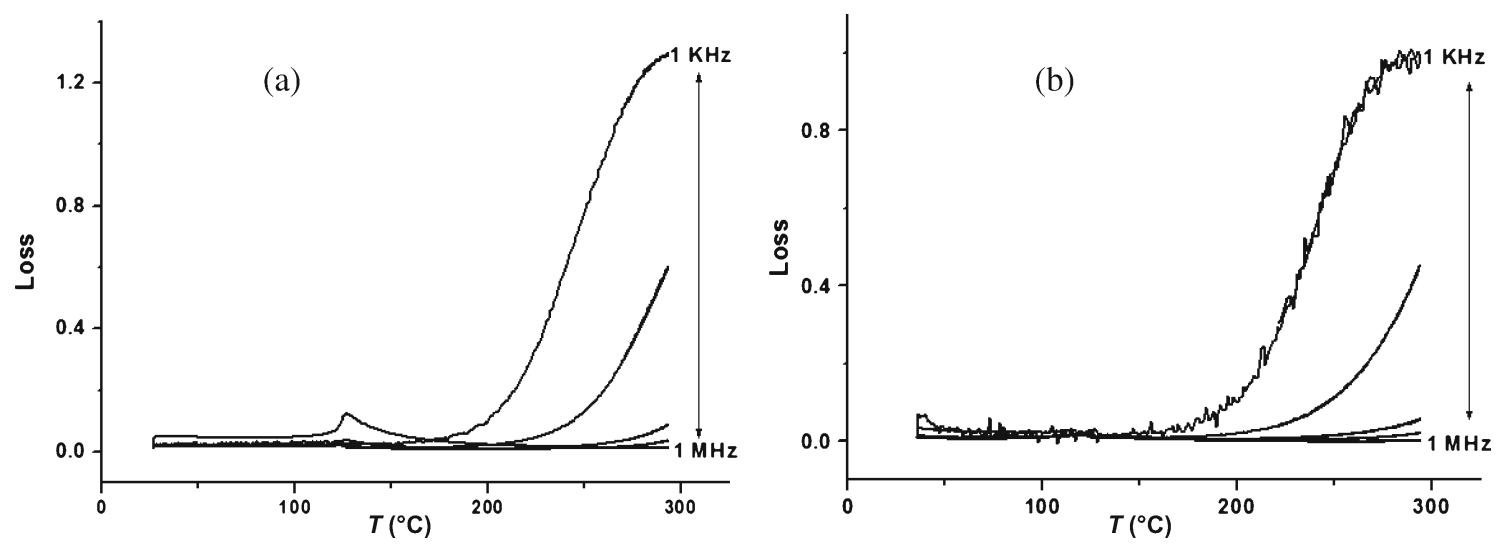

Figure 8. Variation in loss tangent with temperature for (a) pure $\mathrm{BaTiO}_{3}$ sintered at $1250^{\circ} \mathrm{C}$ and $(\mathbf{b}) \mathrm{Li}_{2} \mathrm{CO}_{3}$-added $\mathrm{BaTiO}_{3}$ sample sintered at $1050^{\circ} \mathrm{C}$. 
observed $T_{\mathrm{c}}\left(127^{\circ} \mathrm{C}\right.$ for pure and $124^{\circ} \mathrm{C}$ for $\mathrm{LiCO}_{3}$-added $\mathrm{BaTiO}_{3}$ ) for both compositions is consistent with previous studies (Galasso 1996). The maximum loss tangent values were $\sim 0.035$ (at $1 \mathrm{kHz}$ ) to 0.007 (at $1 \mathrm{MHz}$ ) up to $\sim 175^{\circ} \mathrm{C}$, but increased on further increase in temperature (figure 8 ).

\section{Conclusions}

The fabrication of $\mathrm{BaTiO}_{3}$ via reactive liquid phase sintering has the potential to enhance the density of parts at relatively low temperatures as compared to the mixed-oxide route. Additions of $0.3 \mathrm{wt} \% \mathrm{Li}_{2} \mathrm{CO}_{3}$ as a fluxing agent/sintering aid significantly reduced the optimal sintering temperature by $\sim 200^{\circ} \mathrm{C}$ and reduced the grain size from $\geq 2-10 \mu \mathrm{m}$ to $\leq 1-1.5 \mu \mathrm{m}$. The phase transitions in the flux-added samples occurred relatively slowly in comparison to the pure samples. In contrast to previous studies of flux-added $\mathrm{BaTiO}_{3}$, the final ceramic was single phase in the present study.

\section{Acknowledgements}

The authors acknowledge the financial support of the Higher Education of Pakistan via NRPU Project No. 20569 and Development of Materials Connection Project, the US National Academy of Sciences under the Pak US S\&T Cooperation Program, Award No. PGA-P280420, and Prof. I M Reaney for facilitating one of the authors in electrical properties measurement.

\section{References}

Anan'eva A A, Strizkov B W and Ugryumova M A 1960 Bull. Acad. Sci. USSR Phys. Ser. 241395
Batllo F, Duverger E, Jules J C, Claudeniepec J, Jannot B and Maglione M 1990 Ferroelectrics 109113

Bell A J 2008 J. Euro. Ceram. Soc. 281307

Bunting E N, Shelton G R and Creamer A S 1947 J. Am. Ceram. Soc. 30114

Cheng S, Fu S and Wei C 1989 Ceram. Int. 15231

Desu S B and Subbarao E C 1981 Ferroelectrics 37665

Galasso F S 1996 Structure, properties and preparation of perovskite-type compounds (Oxford: Pergamon Press)

Heartling G H 1999 J. Am. Ceram. Soc. 82797

Hsiang H, Hsi C, Huang C and Fu S 2009 Mater. Chem. Phys. 113 658

Jaffe B and Cook W R 1971 Piezoelectric ceramics (London: Academic Press)

Kong M, Jiang S, Xie T and Zhang H 2009 Microelec. Eng. 862320

Langhammaer H T, Muller T, Felgner K H and Abicht H P 2000 J. Am. Ceram. Soc. 83605

Li Q, Qi J, Wang Y, Gui Z and Li L 2001 J. Eur. Ceram. Soc. 21 2217

Manczok R and Wernicke R 1983 Philips Tech. Rev. 41338

Masion W R, Kleeberg R, Heimann R B and Phanicphant S 2003 J. Eur. Ceram. Soc. 23127

Millsch B 2006 Phys. Status Solidi (a) 133455

O'Bryan Jr. H M and Thomson Jr. J 1974 J. Am. Ceram. Soc. 57522

Pasha U M, Zheng H, Thakur O P, Feteira A, Whittle K R, Sinclair D C and Reaney I M 2007 Appl. Phys. Lett. 91062908

Qiao L, Zhou H, Chen K and Fu R 2003 J. Eur. Ceram. Soc. 23 1517

Scott A W 1993 Understanding microwaves (New York: John Wiley \& Sons)

Shannon R D 1993 J. Appl. Phys. 73348

Swartz S L and Shrout T R 1997 J. Am. Ceram Soc. Bull. 7659

Valant M, Suvorov D, Pullar R C, Sarma K and Alford N M 2006 J. Eur. Ceram. Soc. 262777

Wang L H 2002 Structure and dielectric properties of perovskitebarium titanate $\left(\mathrm{BaTiO}_{3}\right)$ (Peshawar: San Jose State University)

Wul B 1945 Nature 156480 